\title{
Conditional factors for untreated caries in 12-year-old children in the city of São Paulo
}

Raquel Marianna Lopes(a) Gabrielle Gonsalli Domingues ${ }^{(a)}$ Simone Rennó Junqueira(b) Maria Ercilia de Araujo(b) Antônio Carlos Frias ${ }^{(b)}$

(a) Programa de Iniciação Científica, Faculdade de Odontologia, Univ de São Paulo - USP, São Paulo, SP, Brasil.

(b) Departamento de Odontologia Social, Faculdade de Odontologia, Univ de São Paulo - USP, São Paulo, SP, Brasil.
Declaration of Interests: The authors certify that they have no commercial or associative interest that represents a conflict of interest in connection with the manuscript.

\section{Corresponding Author:}

Antônio Carlos Frias

E-mail: acfrias@usp.br

Submitted: Dec 18, 2012

Accepted for publication: May 14, 2013

Last revision: Jun 04, 2013
Abstract: The aim of the study was to analyze what sociodemographic and economic variables were associated with the presence of untreated caries in 12-year-old children in the city of São Paulo. This cross-sectional study had a complex sample design. It was based on secondary data generated by the Levantamento epidemiológico em saúde bucal (Epidemiological Oral Health Survey) in the city of São Paulo, conducted in 2008, whose sample comprised 4,246 12-year-old children from the public and private schools of all the administrative districts of the city. A questionnaire was applied and an epidemiological exam was performed in accordance with the World Health Organization's (WHO) recommendations. The variables of interest were categorized into a dependent variable of untreated dental caries (carious component of the DMFT index that corresponds to carious, missing and filled teeth) and independent variables related to the socioeconomic and demographic conditions of the children and their families, and to their access to dental services. The EPI-INFO 06 and STATA 10 programs were used for the analysis; the prevalence ratio and a confidence interval of $95 \%$ were applied to the population parameters. The Poisson regression model was used, adjusted for sampling of the complex type. Caries was associated with ethnicity (higher rate in black people, $p=0.042)$, attending public school $(p=0.000)$, lower average family income $(p=0.002)$, overcrowded dwellings $(p=0.000)$ and presence of pain $(p=0.000)$. Caries is a multifactorial disease influenced by social health determinants that intensify its risk.

Descriptors: Dental Caries; Social Conditions; Health Services Accessibility; Pain.

\section{Introduction}

Caries is a multifactorial disease that affects not only people's eating and oral hygiene habits, but also their living standards. ${ }^{1-9}$

Studies have shown that socioeconomic and demographic factors are related to the presence of caries. The highest prevalence and incidences of the disease are associated with poor social, economic and demographic conditions. ${ }^{2,5,9,10}$

Thus, the social condition-in which ethnicity, family income and parents' degree of schooling, overcrowded dwellings, and access to healthcare services may be considered predisposing factors-defines a child's profile with regard to caries. ${ }^{5,7,11}$ 
Epidemiological data have shown the polarization phenomenon of caries over the last decades, ${ }^{4,6,8}$ in which distribution of the disease is concentrated in the third of the population with the greatest social deprivations.

The decrease in the DMFT (an index corresponding to the mean number of carious, missing and filled permanent teeth) in 12-year-olds confirms the decline in caries, attributed to the expansion of public water supply fluoridation, introduction of fluorinated dentifrices on the market and preventive measures introduced through public healthcare programs. Moreover, it signals a redistribution of the disease that affects children unequally. , $^{2,7,7,8,10}$

The last epidemiological oral health survey (2008) conducted in public and private schools in the city of São Paulo, with a representative sample of all the administrative districts, indicated a low prevalence of caries in 12-year-olds (DMFT $=1.32)$.

Even if the preventive methods assuring good oral health conditions are maintained, it is important to focus on the aspects related to polarization of the disease, and to identify the predisposing factors, so that the suffering of those who still have untreated caries, and are consequently in pain, may be minimized. ${ }^{11}$

The objective of this study was to determine which of the socioeconomic and demographic variables were associated with untreated caries in 12-year-old children in the city of São Paulo, in 2008.

\section{Methodology}

This cross-sectional study had a complex sampling design. It was based on secondary data generated by the epidemiological oral health survey conducted by the Secretaria Municipal da Saúde in the city of São Paulo, in 2008. The sample comprised 4,246 12-year-old children from public and private schools of all the administrative districts of the city. ${ }^{12}$

The epidemiological survey was approved by the Ethics Committee of the Secretaria Municipal da Saúde (Protocol \#48/08). It was conducted in 1,371 public and 374 private schools, between September and December 2008. At that time, 5,858 children between 18 and 36 months old, 5,557 5-year-old children, 4,249 12-year-old children and 2,858 adolescents between 15 and 19 years old, for a total of 18,522 children, were examined. Their parents or guardians answered a questionnaire to enable social characterization, which included information on access to dental services.

The survey report explained the training and calibration procedures of the dentists who worked as examiners, and presented data on interexaminer precision, which assured reliability. The value of the kappa statistics for assessment of the dental caries condition was $0.954(\mathrm{CI}=0.94-0.96)$.

\section{Definition of variables}

Dental caries was defined as a dependent variable, and the carious component was selected by means of the DMFT index. The independent variables and the other socioeconomic and demographic conditions of the children and their families, as well as their treatment needs and access to oral health services, were also established.

First, the variables of the epidemiological survey database were dichotomized. The dependent variable was classified as untreated caries (present versus absent). The independent variables were classified according to the socio-demographic conditions, such as gender (male versus female), ethnic group (black/brown versus white), overcrowded dwellings ( 1 or more people per room versus less than 1 person per room); socioeconomic conditions, such as type of school (public versus private), parents' education and years of schooling (elementary school versus high school or university), family income (up to 1 minimum monthly wage versus more than 1 minimum monthly wage), owning of a car (yes versus no); access to services such as those of a dentist (has been to a dentist versus has never been to a dentist), last appointment (over 2 years ago versus 1 year ago or less), place of the last appointment (public versus insurance-associated/private establishment), access to oral hygiene information (had no access versus had access) and aggravating conditions, such as need for endodontic treatment (yes versus no), need for surgical treatment (yes versus no), and report of pain (yes versus no). 


\begin{tabular}{|c|c|c|c|c|c|c|c|c|c|c|}
\hline \multirow{2}{*}{$\begin{array}{r}\text { Table } 1 \text { - Mean dental caries in } \\
\text { permanent dentition, determined } \\
\text { by the DMFT index and its } \\
\text { components, standard error, }\end{array}$} & & \multirow{2}{*}{$n$} & \multirow{2}{*}{$\mathrm{D}$} & \multirow{2}{*}{ M } & \multirow{2}{*}{$F$} & \multirow{2}{*}{ DMFT } & \multirow{2}{*}{$\begin{array}{l}\text { Standard } \\
\text { error }\end{array}$} & \multicolumn{2}{|c|}{ Cl 95\%* } & \multirow{2}{*}{$\begin{array}{c}\% \text { Free o } \\
\text { caries }\end{array}$} \\
\hline & & & & & & & & Over & Under & \\
\hline $\begin{array}{l}\text { components, standard error, } \\
\text { confidence interval and percentage }\end{array}$ & $\begin{array}{l}12 \text { year-olds } \\
\text { in São Paulo }\end{array}$ & 4249 & 0.81 & 0.03 & 0.49 & 1.32 & 0.054 & 1.21 & 1.42 & 54.8 \\
\hline
\end{tabular}
city of São Paulo, 2008.

\section{Data analysis}

The EPI-INFO software, version 6.4, of public domain, developed by the Centers for Disease Control and Prevention (CDC, Atlanta, USA) for the World Health Organization was used to set up the database and afford information input.

After the database setup, bivariate association between the dependent and the independent variables was compiled on the Excel program (Microsoft, Seattle, USA). The prevalence ratio, considering a confidence interval of $95 \%$, was used to establish the population parameters. The variables that presented significant association were reorganized for further multivariate association.

A prevalence ratio and confidence interval of 95\% was used to establish the population parameters for the multivariate association, performed by the STATA 10 program (StataCorpLP, College Station, USA). The Poisson regression model was used, adjusted for the complex type of sampling, considering the population size.

\section{Results}

Table 1 presents the results of the mean DMFT index and its components, the confidence interval and the percentage of dental caries-free children in the city of São Paulo, in 2008.

The results of the bivariate analysis presented in Table 2 indicated a significant association of untreated caries with demographic and socioeconomic variables, such as ethnicity, crowding, type of school, parents' level of education, family income, owning of a car and presence of pain. This association signaled that children may present more risks, may have untreated caries, and, consequently, may suffer more pain, depending on the social integration of their families.

When each variable is analyzed individually, the children may present more risks of having untreated caries, and may consequently suffer more pain, depending on the social integration of the families.

The multivariate analysis showed that there was a significant association between the dependent variable (untreated caries) and the socioeconomic and demographic variables in the 12-year-old children (Table 3).

Untreated caries was more prevalent among the black and/or brown children who went to public schools, presented pain in the last 6 months, lived in a dwelling with more than one person per room, and came from a family whose income was lower than or equal to 1 minimum monthly wage.

\section{Discussion}

The presence of caries is related to both oral hygiene and sociodemographic conditions..$^{1-3,5,7-9}$

Scientific evidence has shown that the high intake of sweets, associated with a low family income, results in children with the most severe form of the disease. $^{2}$

The highest concentration of caries was found to be more prevalent in 12-year-old children from less socially privileged families. ${ }^{13}$ Clinical, economic and psychosocial factors, as well as the using of dental services, were variables strongly associated with the occurrence of caries. ${ }^{14}$

The prevalence of caries, therefore, reflects an association between determinant factors of a biological and socioeconomic nature. ${ }^{1,5}$

A greater exposure to a fluoridated water supply and the use of fluoride dentifrices have been the main factors responsible for the reduction in caries prevalence. However, studies have stressed that the polarization of caries is a phenomenon that is occurring at the present time, and that the caries problem has become more intense in a small portion of the 
Table 2 - Association of untreated caries in children with sociodemographic and socioeconomic access to dental services, and oral health condition variables in 12-year-old schoolchildren living in the city of São Paulo, 2008.

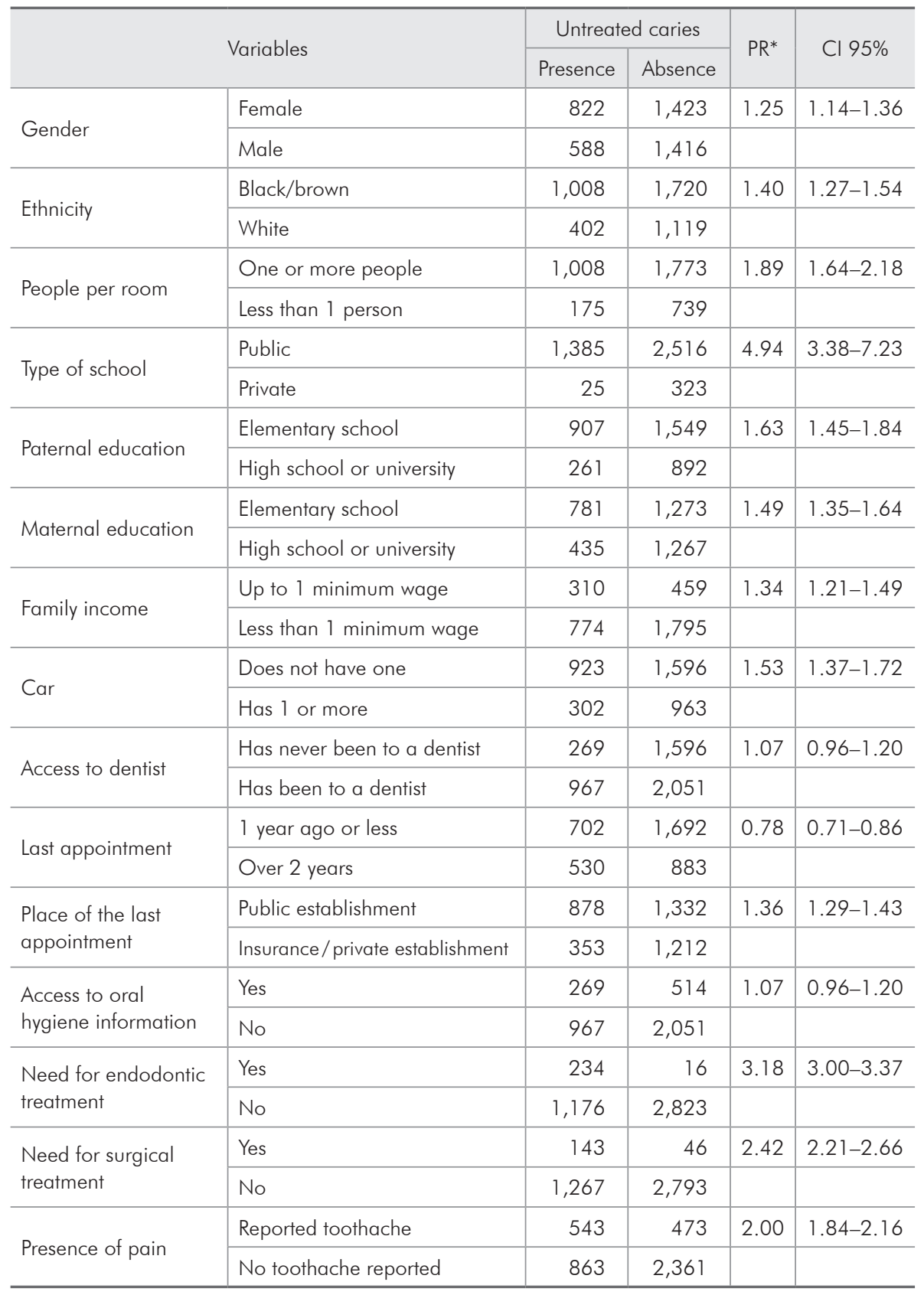

*PR: prevalence ratio adjusted for the sampling model per conglomerate, and considering the population size. population. ${ }^{4,7,8}$

The aim of the present study was to identify untreated caries among children who live in the city of São Paulo, and establish what factors could be associated with untreated caries in those with the disease.

In one of the pioneer studies addressing ethnicity, 860 schoolchildren of both genders, white and non-white skinned, between the ages of 7 and 12, from seven orphanages in the city of São Paulo, were examined to determine if there were differences in their caries experience, considering that they lived in the same socioenvironmental conditions. The results confirmed that there was no difference in the prevalence of caries in relation to ethnicity. ${ }^{15}$

However, it is worth emphasizing that the condi- 


\begin{tabular}{|c|c|c|c|c|c|}
\hline & & & & & \\
\hline $\begin{array}{l}\text { Table } 3 \text { - Multivariate analysis } \\
\text { of the factors associated with the }\end{array}$ & Variables & $\mathrm{PR}^{*}$ & $\begin{array}{l}\text { Standard } \\
\text { error }\end{array}$ & $\mathrm{Cl} 95 \%$ & $P$ value \\
\hline caries in 12-year-old schoolchildren & Black/brown skin color & 1,158 & 0.083 & $1.01-1.34$ & 0.042 \\
\hline living in the city of São Paulo, & Goes to a public school & 1,992 & 0.911 & $1.64-5.45$ & 0.000 \\
\hline & Presence of pain in the last 6 months & 1,752 & 0.132 & $1.51-2.03$ & 0.000 \\
\hline & One or more people per room & 1,501 & 0.152 & $1.23-1.83$ & 0.000 \\
\hline & Family income lower or equal to $1 \mathrm{MW}$ & 1,248 & 0.090 & $1.08-1.44$ & 0.002 \\
\hline
\end{tabular}

tions of the 12-year-old children living in the city of São Paulo cannot be compared with those of orphanage children mentioned above, and that, in the present study, there was heterogeneity as regards their living conditions. Therefore, it was not because of the ethnic factor that black or brown children presented more chances of having untreated caries, but because of the social conditions under which they lived.

The type of school attended may reveal a difference in the prevalence of caries. In the study conducted by Maltz and Silva ${ }^{10}$ in Porto Alegre, RS, a difference was observed between the children from public and private schools. The children from public schools presented a DMFT of $2.48 \pm 2.51$, whereas the mean index among the children from private schools was $1.54 \pm 2.02$.

According to Rihs et al., ${ }^{11}$ the presence of pain was related to worse oral health conditions, and also represented a negative aspect as regards the appearance of the teeth of 12-year-old children in the city of Paulínia, in inland São Paulo State.

In the Northeast of the country, the situation was no different. In a study conducted by Noro et al., ${ }^{9}$ the presence of pain in the last 6 months was related to the presence of caries, as well as the school meals, frequency of visits to a dentist in an interval of less than 1 year, and prompt access to a basic health care unit.

The socioeconomic conditions influenced the living conditions of the people in several ways, among which the influence of crowded dwellings stand outs in particular. Higher DMFT values by the age of 7 were found among children of families with a larger number of children, and, therefore, a higher ratio of number of people per room in the dwelling. ${ }^{9}$
One of the most widely studied variables in the characterization of socioeconomic conditions is the average family income. The 12-year-old children whose family had an average income lower than 5 minimum wages had 4.18 more chances of having severe caries than the children from families with an income higher than 5 minimum monthly wages. ${ }^{2}$

São Paulo is the most populated city in the country, and despite its good development indexes, it has many social disparities. The epidemiological oral health survey of $2008,{ }^{12}$ for the first time, allowed children living in all the administrative districts to be included in the sample, thus assuring the representativeness of the city and the reliability of the data, so that local managers could structure their oral health services to fit their local reality.

The profile of the children that presented untreated caries was related to aspects resulting from socioeconomic and demographic conditions. The variable of ethnicity does not result from the genetic factor, but rather, from the social inequality that prevails, and is reflected in the prevalence and incidence of caries among black and/or brown children, and among those who study in public schools, live in a high density family situation, come from families with a low family income and have presented pain in the last 6 months.

Brushing one's teeth and flossing regularly, as a means of controlling bacterial plaque and preventing dental caries, has not yet become part of the daily routine of these children. This study confirmed that the absence of this behavior is determined socially, since caries is significantly more frequent in children from families with lower purchasing power.

Social inequalities may be minimized by more 
just social policies. Some health actions that may be organized regionally and/or locally include:

- ensuring educational oral health programs targeting children, and

- regular and continued distribution of oral hygiene products like toothbrush, toothpaste and floss, mainly in lower income communities and in public schools.

The training and the strengthening of educational oral health activities for all oral health and family health teams is a way of expanding and universalizing these practices, thereby minimizing the perverse effects on oral health caused by precarious living conditions.

\section{References}

1. Peres MAA, Narvai PC, Calvo MCM. Prevalence of dental caries in a 12-year-old population in localities in Southeastern Brazil, during the period 1990-1995. Rev Saude Publica. 1997 Dec;31(6):2115-62. Portuguese.

2. Peres KGA, Bastos JRM, Latorre MRDO. Relationship between severity of dental caries and social and behavioral factors in children. Rev Saude Publica. 2000 Aug;34(4):402-8. Portuguese.

3. Sales-Peres SHC, Bastos JRM. An epidemiological profile of dental caries in 12-year-old children residing in cities with and without fluoridated water supply in the central western area of the State of São Paulo, Brazil. Cad Saude Publica. 2002 Sep-Oct;18(5):1281-8. Portuguese.

4. Cardoso L, Rösing C, Kramer P, Costa CC, Filho LCC. Polarization of dental caries in a Brazilian city without fluoridated water. Cad Saude Publica. 2003 Apr;19(1):237-43. Portuguese.

5. Galindo EMV, Pereira JAC, Feliciano KVO, Kovacs MH. Prevalence of caries and associated factors in children of the Vietnã Community, Recife. Rev Bras Saude Mater Infant. 2005 Jun;5(2):199-208. Portuguese.

6. Martins RJ, Garbin CAS, Garbin AJI, Moimaz SAS, Saliba O. Declining caries rate in a municipality in northwestern São Paulo State, Brazil, 1998-2004. Cad Saude Publica. 2006 Apr;22(5):1035-41. Portuguese.

7. Narvai PC, Frazão P, Roncalli AG, Antunes JLF. Dental caries in Brazil: decline, polarization, inequality and social exclusion. Rev Panam Salud Publica. 2006 Jun;19(6):385-93. Portuguese.

8. Peres SHCS, Carvalho FS, Carvalho CP, Bastos JRM, Lauris JRP. Polarization of dental caries in teen-agers in the Southwest of the state of São Paulo, Brazil. Cienc Saude Colet. 2008 Dec;3(suppl 2):2155-62. Portuguese.

\section{Conclusion}

The determinant factors for presenting untreated caries were:

- being of African descent,

- having gone to a public school,

- having presented pain in the last six months,

- living in a dwelling with a high family density and

- coming from a family having an income lower than or equal to a minimum monthly wage.

\section{Acknowledgments}

The authors wish to thank the Universidade de São Paulo - USP for their institutional scholarship of the scientific initiation program.

9. Noro LRA, Roncalli AG, Mendes Junior FIR, Lima KC. Dental caries incidence in adolescents in a city Northeast Brazil, 2006. Cad Saude Publica. 2009 Apr;25(4):783-90. Portuguese.

10. Maltz M, Silva BB. Relationship between caries, gingivitis and fluorosis and the socioeconomic status among school children. Rev Saude Publ. 2001 Apr; 35(2): 170-6. Portuguese.

11. Rihs LB, Cypriano C, Sousa MLR, Silva RC, Gomes PR. Toothache and its relationship with caries experience in teenagers. Rev Gaucha Odontol. 2008 Oct-Dec;56(4):361-5. Portuguese.

12. São Paulo. Prefeitura do Município de São Paulo. Secretaria Municipal da Saúde. Coordenação da Atenção Básica. Área Técnica de Saúde Bucal. Levantamento epidemiológico em saúde bucal. Cidade de São Paulo, 2008-2009. Resumo da primeira fase: crianças e adolescentes. São Paulo: PMSP; 2009 [cited 2012 Aug 8]. Available from: http://www.prefeitura. sp.gov.br/cidade/secretarias/upload/saude/arquivos/saudebucal/LESB_Resumo_PrimeiraFase.pdf.

13. Piovesan C, Mendes FM, Antunes JLF, Ardenghi TM. Inequalities in the distribution of dental caries among 12-year-old Brazilian schoolchildren. Braz Oral Res. 2011 JanFeb;25(1):69-75.

14. Piovesan C, Antunes JLF, Guedes RS, Ardenghi TM. Influence of self-perceived oral health and socioeconomic predictors on the utilization of dental care services by schoolchildren. Braz Oral Res. 2011 Mar-Apr;25(2):143-9.

15. Castellanos RA. An epidemiological study of dental caries of white and non-white school children of both sexes which are interned in seven orphanages on the city of S. Paulo, Brazil, in 1972. Rev Saude Publica. 1974 Mar;8(1):51-62. 